[Agr. Biol. Chem., Vol. 36, No. 11, p. 2005 2011, 1972]

\title{
Isolation and Characterization of Spawning Inhibitors in Ovary of the Starfish, Asterias amurensis
}

\author{
By Susumu Ikegami, Yuji KamiYa and Saburo Tamura \\ Department of Agricultural Chemistry, \\ University of Tokyo, Burkyo-ku, Tokyo \\ Received May 10, 1972
}

\begin{abstract}
Biologically active substances which inhibit spawning of mature starfish, Asterias amurensis, have been isolated from ovaries of the same organisms and identified as asterosaponins $\mathrm{A}$ and $\mathrm{B}$.
\end{abstract}

It has been established that spawning of starfish is induced by injection of water extract of their radial nerves into the body cavity. ${ }^{1 \sim 3}$ ) The active principle causative of the induction is a polypeptide called "gonadstimulating substance" (GSS), which stimulates gonads to produce a "maturation-inducing substance"." The latter component has been elucidated as 1-methyladenine, and it acts directly on the surface of oocytes to cause maturation. ${ }^{5.6}$ Then, discharge of the eggs from gonophores takes place through dissolution of intercellular cementing substances among the eggs followed by contraction of gonadal cell walls. ${ }^{7}$

On the other hand, it has been known that gonads fail to react to GSS at the earlier stage of breeding season but they become more sensitive toward the end of the season. This suggests that some mechanism may operate inside gonads to suppress spawning. Recently, we showed the presence in gonads of Asterias amurensis and Asterina pectinifera of spawning inhibitors, which counteract the action of GSS to prevent unfavorable spawning early in the breeding season. ${ }^{8}$ As for the Asterina, the active component has been isolated and identified as L-glutamic acid. ${ }^{8,9}$ However, the action of this acid was specific to the Asterina, showning little effect on another species, the Asterias. Accordingly, existence of inhibitors other than L-glutamic acid was expected in the latter starfish, and their isolation from ovaries was attempted.

In the previous communication, the isolation and identification of the spawning inhibitors from the Asterias have been preliminary reported. ${ }^{10}$; Here we wish to describe details of the experimental results.

\section{EXPERIMENTAL AND DISCUSSION}

\section{Collection of organs}

The common Japanese starfish, Asterias amurensis, were collected early in the breeding season of 1967 and 1970 at Tokyo Bay and kept in crawls in the sea or in aquaria supplied with running sea water at Misaki Marine Biological Station. Then, ovaries were isolated from the starfish, immediately frozen and lyophilized. By this treatment, the ovaries could be stored in a desiccator without any appreciable loss of biological activity during more than two years.

\section{Bioassay of spawning inhibitors}

The lyophilized ovaries were homogenized in sea water and centrifuged for $50 \mathrm{~min}$ at $30,000 \times g$ and $2^{\circ} \mathrm{C}$. The supernatant was serially diluted, at concentrations of $2.5 \sim 40$ 
mg dry weight per ml, with sea water in which lyophilized nerve tissue prepared according to the method of Kanatani et al. ${ }^{3}$ had been dissolved at a dose of $10 \mu \mathrm{g} / \mathrm{ml}$.* Into each solution thus prepared was placed an ovarian fragment isolated from the starfish at the height of the breeding season, and the degree of spawning was observed.

As the result, the dried ovaries at a concentration of $10 \mathrm{mg} / \mathrm{ml}$ were found to counteract the action of GSS contained in $10 \mu \mathrm{g}$ of the nerve tissue (Fig. 1). Lyophilized testes prepared in the way similar to that for ovaries showed counteraction at the same concentration. Observation of sperm-shedding in vitro is difficult to assess and ovarian

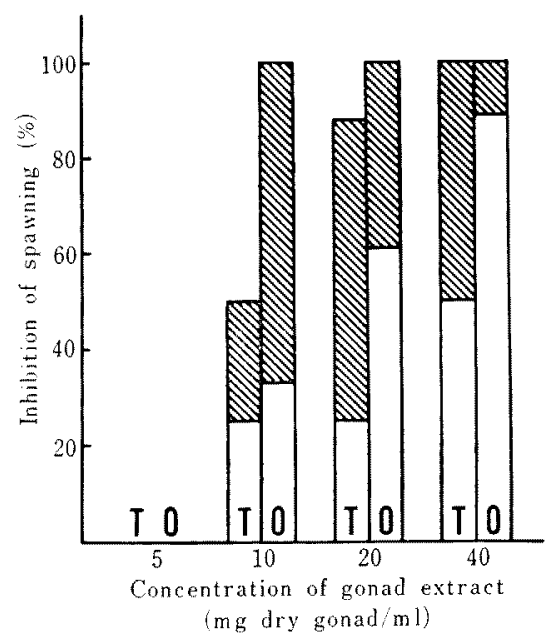

Fra. 1. Inhibition of Spawning by Extracts of Ovary (O) and Testis (T) in Asterias amurensis.

Ovarian fragments were placed in sea water containing various concentrations of gonad extract together with nerve extract $(10 \mu \mathrm{g}$ of lyophilized nerve per $\mathrm{ml}$ ). Shaded columns show incomplete inhibition. Percentage inhibition was calculated from the results of 18 tests for ovary extract and 8 tests for testis extract.

* The minimum dose of the nerve tissue required to bring appreciable discharge of eggs from cut surface of an ovarian fragment was determined, prior to the assay, to be $10 \sim 20 \mu \mathrm{g}$ per $\mathrm{ml}$ of sea water. fragments were employed exclusively throughout the experiment.

Furthermore, in vivo assays were carried out by injecting a solution containing the dry ovary or testis at $10 \mathrm{mg} / \mathrm{ml}$ together with nerve extract ( $10 \mu \mathrm{g}$ lyophilized nerve per $\mathrm{ml}$ ) into the coelomic cavity of either intact male or female starfish. Both ovary and testis extracts were effective to inhibit spawning in females as well as males.

\section{Inhibitory activity of several amino acids} for spawning

Since the spawning inhibitor contained in gonads of the Asterina had been elucidated to be L-glutamic acid, ${ }^{8,9)}$ efficacy of L-glutamic acid as well as of the following L-amino acids was examined for the Asterias: glycine, alanine, serine, threonine, valine, methionine, leucine, isoleucine, phenylalanine, tyrosine, proline, hydroxyproline, tryptophane, aspartic acid, arginine, lysine and histidine.

An ovarian fragment from the Asterias was placed in sea water containing $10^{-2} \mathrm{M}$ of an amino acid together with $20 \mu \mathrm{g} / \mathrm{ml}$ of lyophilized nerve tissue, and the degree of spawning was observed.

None of the amino acids tested showed inhibitory activity. Thus, the presence of spawning inhibitors other than these in the gonad of the Asterias has been proved.

\section{Purification of spawning inhibitors from ovary extract}

Extraction. The spawning inhibitors were isolated from ovaries of Asterias amurensis by the procedure illustrated in Fig. 2.*

Acetone powder $(184 \mathrm{~g})$ prepared from the lyophilized ovaries $(200 \mathrm{~g})$ was extracted with cold $20 \%$ aqueous acetone and filtered. To the filtrate was added cold acetone to make

* The same inhibitors were obtained from lyophilized testes by the similar process. In this paper, however, only the isolation from ovaries is described. 
Ovaries, collected in Dec.

$1-26,1967$ and lyophilized

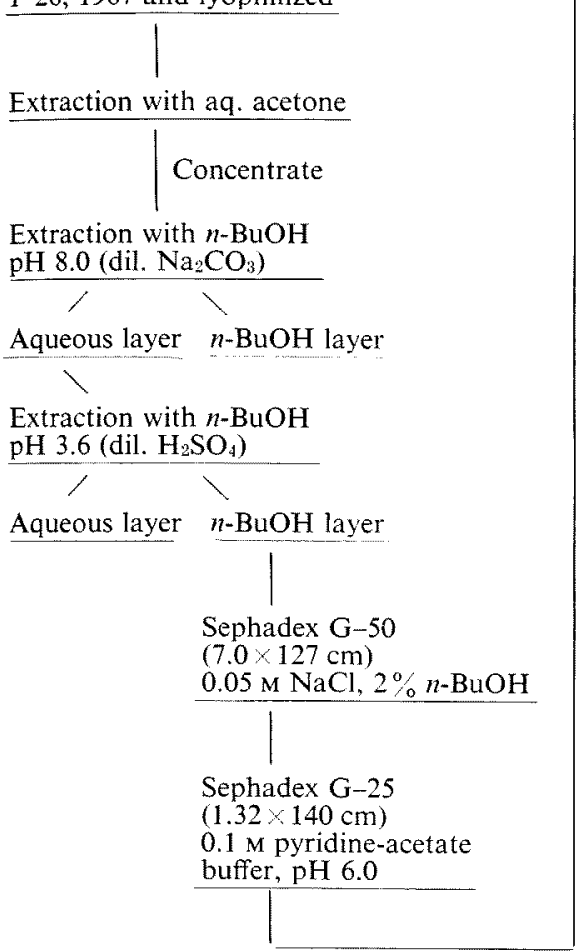

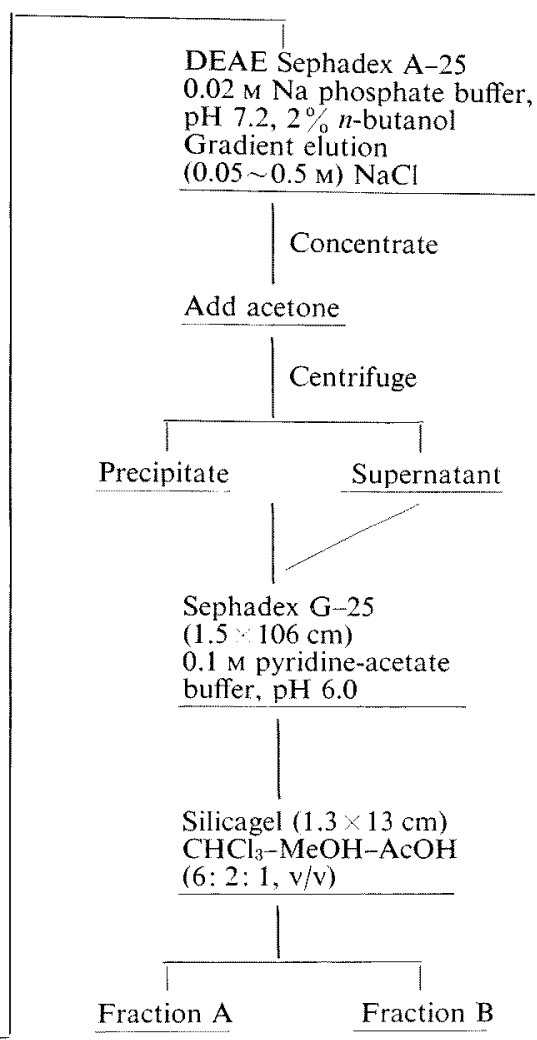

Fig. 2. Procedure for Purifying Spawning Inhibitors from Ovary of Asterias amurensis.

the final concentration $80 \%$. After standing overnight at $3^{\circ} \mathrm{C}$, precipitates were removed by filtration, and the filtrate was concentrated with a rotary evaporator being kept below $40^{\circ} \mathrm{C}$. The aqueous residue was lyophilized and again suspended in distilled water, which was then adjusted to $\mathrm{pH} 8.0$ with dilute sodium carbonate solution and extracted with its equal volume of $n$-butanol. Almost all the biological activity remained in the aqueous phase. After acidification to $\mathrm{pH} 3.6$ with dilute sulfuric acid, the aqueous phase was re-extracted with its equal volume of $n$-butanol. Biological activity was observed in the butanol phase, which was then evaporated to dryness.

Gel-filtration on Sephadex G-50. The solid was dissovled in $10 \mathrm{ml}$ of $0.05 \mathrm{M}$ sodium chlo- ride containing $2 \% n$-butanol and applied onto a Sephadex G-50 column $(7.0 \times 127 \mathrm{~cm})$, which was equilibrated and eluted with the same solvent system (fraction size, $17.5 \mathrm{ml}$; flow rate, $100 \mathrm{ml} / \mathrm{hr} ; 3^{\circ} \mathrm{C}$ ). For the assay of spawning inhibition a portion $(0.2 \mathrm{ml})$ was taken from each fraction and diluted with $3.8 \mathrm{ml}$ of sea water containing GSS. Fractions showing activity were combined and concentrated to $5 \mathrm{ml}$.

Gel-filtration on Sephadex $G-25$. The residual solution was subjected to gel-filtration by use of a Sephadex G-25 column (1.32 $140 \mathrm{~cm}$ ) and $0.1 \mathrm{~m}$ pyridine-acetate buffer of pH 6.0 (fraction size, $7.5 \mathrm{ml}$; flow rate, $70 \mathrm{ml} /$ $\mathrm{hr} ; 3^{\circ} \mathrm{C}$ ). Active fractions were combined and evaporated to dryness. 
Chromatography on DEAE-Sephadex A-25. The solid was dissolved in $150 \mathrm{ml}$ of $0.02 \mathrm{M}$ sodium phosphate buffer ( $\mathrm{pH} 7.5$ ) containing $2 \%$-butanol. The solution was applied onto a DEAE-Sephadex A-25 column $(1.5 \times 10 \mathrm{~cm})$ equilibrated with $0.02 \mathrm{M}$ sodium phosphate buffer ( $\mathrm{pH} 7.2$ ) containing $0.05 \mathrm{M}$ sodium chloride and $2 \% n$-butanol. Linear gradient elution was performed with $0.05 \sim 0.5 \mathrm{M}$ sodium chloride (fraction size, $5 \mathrm{ml}$; flow rate, $40 \mathrm{ml} / \mathrm{hr} ; 6^{\circ} \mathrm{C}$ ). Active fractions eluted with $0.12 \sim 0.33 \mathrm{M}$ sodium chloride were combined and concentrated to $15 \mathrm{ml}$. To the aqueous residue was added $100 \mathrm{ml}$ of cold acetone, and the mixture was centrifuged for $40 \mathrm{~min}$ at $6,000 \times g$. Then the supernatant was evaporated to dryness.

Gel-filtration on Sephadex G-25. The white amorphous powder was dissolved in $5 \mathrm{ml}$ of distilled water and again subjected to gel-filtration by use of a Sephadex G-25 column $(1.5 \times 106 \mathrm{~cm})$ and $0.1 \mathrm{M}$ pyridineacetate buffer of $\mathrm{pH} 6.0$ (fraction size, $2 \mathrm{ml}$; flow rate, $5 \mathrm{ml} / \mathrm{hr} ; 6^{\circ} \mathrm{C}$ ). The active fractions containing little inorganic phosphate and sodium chloride were combined and evaporated to dryness.

Silica gel column chromatography. The solid residue was washed with $4 \mathrm{ml}$ of ethyl acetate to afford a colorless amorphous powder $(191.2 \mathrm{mg})$. The powder $(190 \mathrm{mg})$ was dissolved in $5 \mathrm{ml}$ of chloroform-methanol-acetic acid $(6: 2: 1, v / v)$ and was applied onto a column $(1.3 \times 13 \mathrm{~cm})$ of silica gel (Merck), which was eluted with the same solvent system (fraction size, $10 \mathrm{ml}$; flow rate, $20 \mathrm{ml} / \mathrm{hr}$ ). Each fraction was subjected to thin layer chromatography (TLC) on a Kieselgel $\mathrm{GF}_{254}$ plate of $0.375 \mathrm{~mm}$ thickness and was developed with chloroform-methanol-acetic acid-water (30: 10:5:2, v/v) (Solvent A). Spots were detected under a UV lamp at $2537 \AA$ or by spraying $10 \%(\mathrm{w} / \mathrm{v})$ phosphotungstic acid in ethanol. Fractions No. 11 20 (Fraction A) showed a spot at $R f 0.15$ and fractions No. 26 40 (Fraction B) at $R f 0.07$. On evaporation fractions $A$ and $B$ afforded $68.9 \mathrm{mg}$ and $41.1 \mathrm{mg}$ of solids, respectively.

Purity of spawning inhibitors isolated. Purity of each sample thus obtained was examined in the following ways. With each sample, TLC [Kieselgel $\mathrm{GF}_{254}$ with $70 \%$ aqueous $n$-propanol or $n$-butanol-acetic acid-water (12: $3: 5, \mathrm{v} / \mathrm{v})$; Avicel with $n$-butanol-pyridinewater $(12: 4: 5, \mathrm{v} / \mathrm{v})$ or $n$-butanol-acetic acidwater $(12: 3: 5, \mathrm{v} / \mathrm{v})]$ as well as paper electrophoresis $[0.1 \mathrm{M}$ pyridine-acetate buffer $(\mathrm{pH}$ 6.0)] gave a single spot under a UV lamp or with phosphotungstic acid spray.

Biological activity of inhibitors. Both samples were assayed to determine minimum effective doses against the action of $10 \mu \mathrm{g}$ of the lyophilized nerve. The inhibitor from Fraction A showed inhibition at 12.5 125 $\mu \mathrm{g} / \mathrm{ml}$ and that from Fraction B at $63 \sim$ $125 \mu \mathrm{g} / \mathrm{ml}$.

\section{Identification of spawning inhibitors}

Both samples from Fractions A and B caused hemolysis and easily foamed in water indicating themselves as saponine-like substances.

Identification of inhibitor from Fraction $A$. The UV spectrum of Fraction A in water showed an absorption maximum at $244 \mathrm{~m} \mu$ on a Cary-14 spectrophotometer. The IR spectrum (Fig. 3) run on a JASCO IR-S spectrometer in Nujol mull was similar to that of asterosaponin $\mathrm{A}$, which had been isolated by Yasumoto et al. ${ }^{11)}$ from the same organism.

Further, TLC by use of a Kieselgel $G_{254}$ plate and solvent $\mathrm{A}$ revealed identical $R f$ values at 0.15 for asterosaponin $\mathrm{A}$ and Fraction A. 


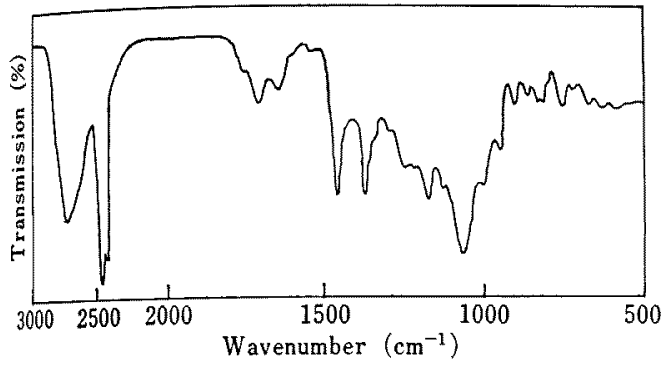

FIG. 3. IR Spectrum of the Inhibitor from Fraction A.

Then, the inhibitor $(10 \mathrm{mg})$ from Fraction A was hydrolyzed with $2 \mathrm{ml}$ of $2 \mathrm{~N}$ hydrochloric acid in a boiling water bath for $2 \mathrm{hr}$. The hydrolyzate was extracted with chloroform, which was washed successively with saturated sodium bicarbonate solution and water. A brown gum $(4.1 \mathrm{mg})$ obtained after evaporation of the solvent showed the presence of at least six components on a Kieselgel $\mathrm{GF}_{254}$ plate which was developed with benzeneacetone $(3: 2, v / v)$. The chromatogram was identical with that of a crude mixture of aglycones separated from asterosaponin A by the same procedure. On each chromatogram, two components with $R f$ values of 0.29 (Fraction 2) and 0.39 (Fraction 1) were dominant. The chemical structure of Fraction 2 has been established recently as $3 \beta, 6 \alpha-$ dihydroxy-5 $\alpha$-pregn-9(11)-en-20-one by the present authors. ${ }^{12)}$ Fraction 1 was further fractionated into several components, whose isolation and characterization will be reported in the near future.

Yasumoto et al. ${ }^{11)}$ reported that asterosaponin A contains one mole of sulfuric acid and two moles each of 6-deoxy-D-glucose and 6-deoxy-D-galactose. In the present study, the aqueous layer remaining after chloroform extraction of the acid hydrolyzate of the inhibitor was subjected to analysis for sulfuric acid content by the method of Dodgson ${ }^{13}$ as well as for hexose content with the phenol- sulfuric acid reagent. ${ }^{14)}$ Sixty $\mu \mathrm{g}$ of sulfuric acid and $450 \mu \mathrm{g}$ of hexose were found to be present in the hydrolyzate from $1 \mathrm{mg}$ of the inhibitor.

Further, a small portion of the aqueous layer was evaporated to dryness, and the remaining solid was subjected to trimethylsilylation. ${ }^{15)}$ A mixture of $O$-trimethylsilyl (TMS) derivatives was subjected to gas-liquid chromatography (GLC) by use of a Hitachi gas chromatograph, Model K-53, equipped with a hydrogen flame ionization detector. A glass column $(0.3 \times 200 \mathrm{~cm})$ was packed with $3 \%$ OV -1 on Chromosorb W $(80 \sim 100$ mesh $)$ and was maintained at $150^{\circ} \mathrm{C}$. The flow rate of the carrier gas, nitrogen, was $40 \mathrm{ml}$ per min. Three peaks with retention times corresponding to the TMS derivative of 6-deoxy-D-galactose were detected at 4.8, 5.6 and $6.7 \mathrm{~min}$, and two peaks responsible for the TMS derivative of 6-deoxy-D-glucose at 7.8 and $10.7 \mathrm{~min}$ (Fig. 4). On the basis of calculation for peak areas, 6-deoxy-D-galactose and 6-deoxy-D-glucose

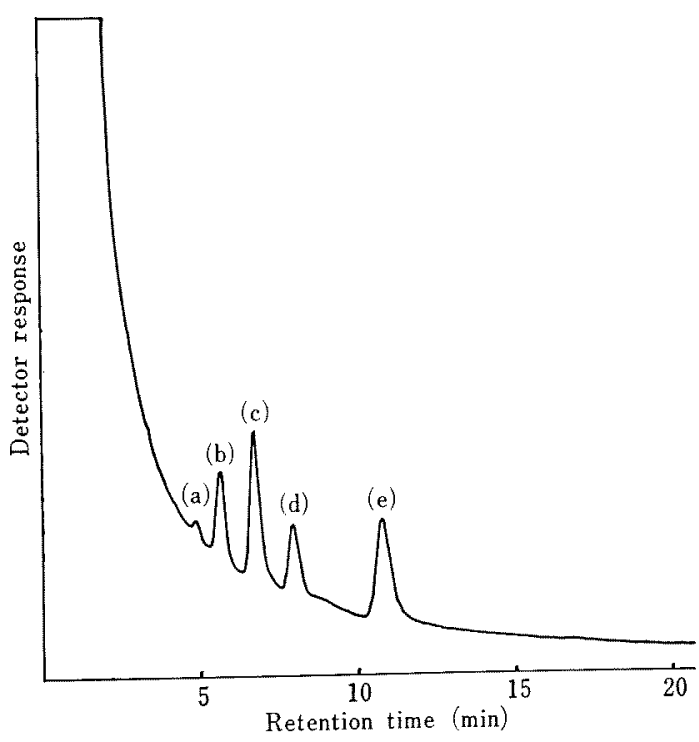

FIG. 4. Gas Chromatogram of TMS Derivatives of Hydrolyzate of Fraction A.

(a), (b) and (c): TMS of 6-deoxygalactose, (d) and (e): TMS of 6-deoxyglucose. 
were found to exist in an equimolar ratio. Thus, the inhibitor from Fraction $\mathrm{A}$ has been established to be identical with asterosaponin A.

Identification of inhibitor from Fraction $B$. The inhibitor in water showed a UV maximum at $244 \mathrm{~m} \mu$. The IR bands $\left(\nu_{\mathrm{max}}^{\mathrm{NujO1}} \mathrm{cm}^{-1}: 3500\right.$, $1700,1670,1650,1180,1050$ and 960) were similar to those of asterosaponin B reported by Yasumoto et al. ${ }^{16)}$ When subjected to TLC by use of Kieselgel $G_{254}$ and Solvent $A$, the inhibitor and asterosaponin $B$ showed identical spots at $R f 0.07$.

The GLC pattern of TMS derivatives obtained from an acid hydrolyzate of the inhibitor is shown in Fig. 5. In addition to

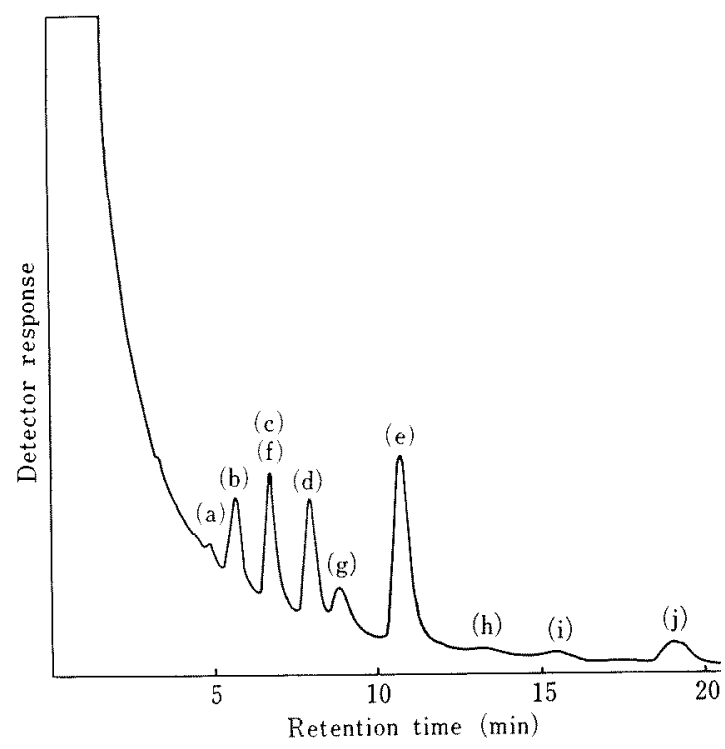

FIG. 5. Gas Chromatogram of TMS Derivatives of Hydrolyzate of Fraction $\mathbf{B}$.

(a), (b) and (c): TMS of 6-deoxygalactose; (d) and (e): TMS of 6-deoxyglucose; (f) and (g): TMS of xylose; (h), (i) and (j): TMS of galactose.

the peaks responsible for the TMS derivatives of 6-deoxy-D-galactose and 6-deoxy-D-glucose, two peaks ascribable to $D$-xylose (retention times; 6.8 and $8.8 \mathrm{~min}$ ), and three peaks to
D-galactose (retention times; 13.2, 15.3 and $18.9 \mathrm{~min}$ ) were observed. The molar ratio of 6-deoxy-D-glucose, 6-deoxy-D-galactose, Dxylose and D-galactose was established as 2:1:1:1. These data were consistent with those assigned for asterosaponin B by Yasumoto et al. ${ }^{16)}$

Inhibitory activity of asterosaponins $A$ and $B$. When the authentic asterosaponins $A$ and $B$ were subjected to bioassay, the saponin $A$ at the concentrations of $12.5 \sim 125 \mu \mathrm{g} / \mathrm{ml}$ effectively inhibited the action of lyophilized nerve at a dose of $10 \mu \mathrm{g} / \mathrm{ml}$ and the saponin B did at $63 \sim 125 \mu \mathrm{g} / \mathrm{ml}$. These values correspond well with those of the inhibitors mentioned above.

Yasumoto et al. described that asterosaponins distribute in every part of the starfish in high concentrations during summer whereas contents of the saponins are extremely low and found only in gonads during winter when the animals are at the breeding season at Tokyo Bay. ${ }^{17)}$ Further, GSS is present almost at the constant concentration in the radial nerves throughout the year, ${ }^{2,3}$ but only induces spawning during a short period each year. This annual change might correspond to the aforementioned physiological action of asterosaponins.

Acknowledgement. The authors thank Prof. $\mathrm{H}$. Kanatani and Dr. H. Shirai of Ocean Research Institute, University of Tokyo for their advice and help and the staff members of Akkeshi and Misaki Marine Biological Stations for research facilities. They are also grateful to Prof. T. Yasumoto of Tohoku University and Prof. Y. Hashimoto of University of Tokyo for their supply of asterosaponins.

\section{REFERENCES}

1) A. B. Chaet and R. A. McCconaughy, Biol. Bull., 117, 407 (1959).

2) A. B. Chaet, ibid., 130, 43 (1966).

3) H. Kanatani and M. Ohguri, ibid,. 131, 104 (1966).

4) H. Kanatani, S. Ikegami, H. Shirai, H. Oide and 
S. Tamura, Development, Growth and Differentiation, 13, 151 (1971).

5) H. Kanatani and H. Shirai, Nature, 216, 284 (1969).

6) H. Kanatani, H. Shirai, K. Nakanishi and T. Kurokawa, ibid., 221, 273 (1969).

7) H. Kanatani, Science, 146, 1177 (1964).

8) S. Ikegami, S. Tamura and H. Kanatani, ibid., 158, 1052 (1967).

9) S. Ikegami and S. Tamura, Agr. Biol. Chem., 36, 1899 (1972).

10) S. Ikegami, Y. Kamiya and S. Tamura, ibid., 36, 1087 (1972).

11) T. Yasumoto and Y. Hashimoto, ibid., 29, 804
(1965).

12) S. Ikegami, Y. Kamiya and S. Tamura, Tetrahedron Letters, 1972, 1601.

13) K. S. Dodgson, Biochem. J., 78, 312 (1961).

14) J. E. Hodge, B. T. Hofreiter, "Methods in Carbohydrate Chemistry," Vol. I, ed. by R. L. Whistler and M. L. Wolfrom, Academic Press, New York, 1962, p. 388.

15) C. C. Sweeley, R. Bentley, M. Makita and W. W. Wells, J. Am. Chem. Soc, 85, 2497 (1963).

16) T. Yasumoto and Y. Hashimoto, Agr. Biol. Chem., 31, 368 (1967).

17) T. Yasumoto, M. Tanaka and $Y$. Hashimoto, Bull. Jap. Soc. Sci. Fisheries, 32, 673 (1966). 